\title{
ROCK
}

FAILURE

\section{Effect of Geological and Geophysical Characteristics of Complex-Structure Ferruginous Quartzite Ore Bodies on Blasting and Processing Performance

\author{
V. N. Tyupin ${ }^{a *}$ and V. N. Anisimov ${ }^{b * *}$ \\ ${ }^{a}$ Belgorod State National Research University, Belgorod, 308015 Russia \\ *e-mail:tyupinvn@mail.ru \\ ${ }^{b}$ Institute of Geosphere Dynamics, Russian Academy of Sciences, Moscow, 119334 Russia \\ **e-mail: vicnican@ya.ru
}

Received March 14, 2017

\begin{abstract}
In terms of the complex-structure ferruginous quartzite ore body mining in the Kursk Magnetic Anomaly, the authors validate the requirement to account for anisotropy of rocks with a view to improving performance of preparatory and blasting operations, stabilizing grain size composition, reducing production of oversizes, saving energy input of milling, enhancing useful component extraction into concentrate and decreasing losses with regard to the sound subsoil management conditions. The effect of the first to third scale anisotropy on the quality of blasting fragmentation of ferruginous quartzite is analyzed. The theoretical formulas to calculate radius of controlled fragmentation zone as function of geological and geophysical characteristics of rock mass are presented, and the practical results of blasting at open pit mines in the Kursk Magnetic Anomaly area are described.

Keywords: Mining, blasting direction, three-dimensional position, rock mass elements, fold pivot axis, core, wing, anticline, syncline, bedding, orientation, dip angle, controlled grain size composition, oversize yield.
\end{abstract}

DOI: $10.1134 / \mathrm{S} 106273911801333 \mathrm{X}$

\section{INTRODUCTION}

Investigations of ferruginous quartzite reserves of the Kursk Magnetic Anomaly (KMA) show that one of the most important properties of these complex structure masses, alongside with jointing, fracturing, strength and elasticity, is anisotropy. Anisotropy takes a specific part in substantiation of applicability of blasting in iron ore mining, with regard to genesis of ore bodies, geological and geophysical characteristics, as well as conditions and standards of efficient subsoil management, in order to adjust drilling and blasting designs at both operating and new mines [1]. Effect of hierarchical block structure or rock mass, including different scale anisotropy, on mining was analyzed in [2-6].

Inclusion of geological and geophysical characteristics of rocks in the design of development and drilling-and-blasting patterns enables selection of a correct advance of mining based on conditions and standards of efficient subsoil use. As a consequence, arrangement of new free surfaces of blocks and direction of breakage agree with the basic structural elements of rock mass: pivots of anticline and syncline folds, core and wings of folds, orientation of bedding and dip angle of pivots and wings of folds. Such methodological approach considerably improves quality of ore pre-treatment by blasting as well as mine performance, reduce yield of oversize, saves energy spent for milling, lowers loss of useful components in tailings, and increases yield of useful components in concentrate [6,7]. In this connection, anisotropy is of specific value. 


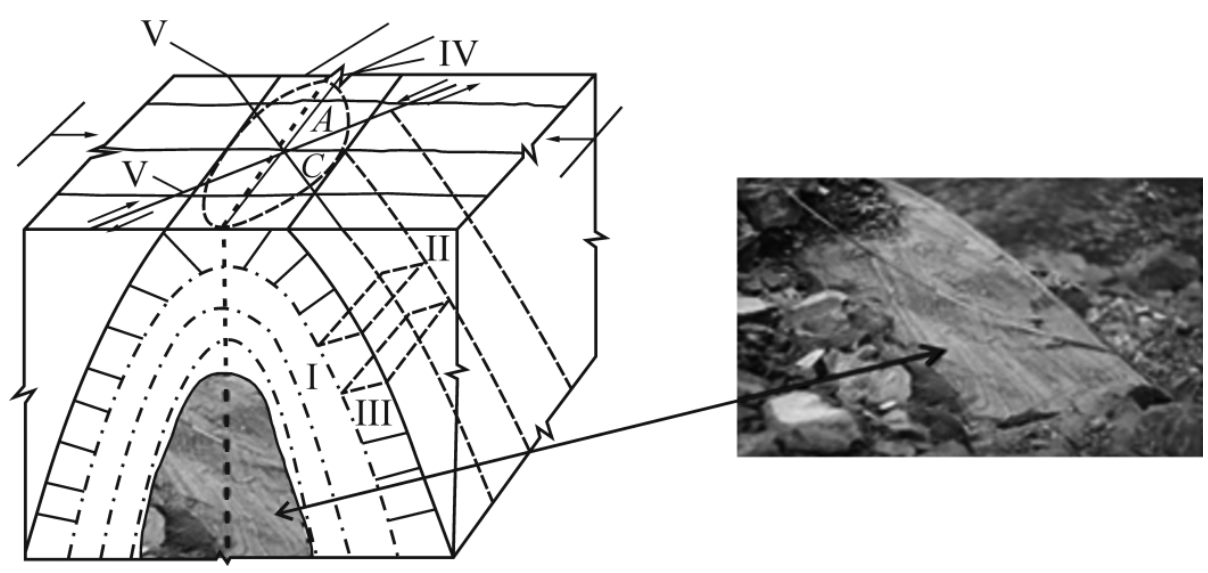

Fig. 1. Elements of axial zone of fold core and orientation of natural fractures relative to the fold pivot: $A-$ axis of pivot of anticline fold; $C$-axis of pivot of syncline fold; $\mathrm{I}-\mathrm{V}-$ scales of anisotropy.

It is known that anisotropy of hard rock masses is first of all connected with their genesis, particularly at ferruginous quartzite deposits of KMA with their pronounced shistocity, jointing and fracturing related with the basic structural elements such as pivots, cores and wings of folds (Fig. 1).

Anisotropy of hard rocks can be governed by tectonics, e.g. movement of crust plates, as well as by faulting. There are a number of scales of anisotropy [8]:

- anisotropy connected with the occurrence of rocks in the form of synclines, anticlines and series of linear folds (scale I);

— anisotropy caused by macrofracturing and bedding of rocks (sale II);

- petrographic anisotropy governed by microfracturing; it shows itself in anisotropy of rock specimens (scale III);

- anisotropy of crystals governed by the ordered structure of crystalline lattice (scale IV).

The representative anisotropic rock masses are complex-structure ferruginous quartzite bodies of KMA. These bodies are structures with the pronounced bedding, alternation of axes of pivots of different scale anticline and syncline folds, fracturing, jointing, wings of folds and compact strong cores. All these structural elements imply anisotropic properties of rock mass.

In order to improve quality of blasting and further processing, blast designs in complex-structure bodies of ferruginous quartzite should taken into account anisotropy of scales I-III.

\section{GENERAL PROVISIONS}

Experience of blasting shows that anisotropy of scales II-III (macro- and micro-fracturing) determines a fragmentation zone radius in rock mass and, consequently, the spacing of charges and burden; anisotropy of scale I-direction of blasting, i.e. arrangement of a simultaneously blasted row relative to fold pivot axis, location of newly formed free surface (Fig. 2).

The investigations of KMA launched in the early 1980s prove that proper inclusion of anisotropy in blast design and mine planning essentially improves efficiency of milling and dissociation of grains of rock-forming minerals. The effect takes place owing to utilization of the relationship between orientation of shear stress and directions of strike and dip of mineral beds, which is inseparably connected with spatial arrangement and alteration of axes of pivots of different-scale anticline and syncline folds (Fig. 2) [1, 6, 7]. On this basis, the procedure of blast design and assessment of blast impact on grinding and beneficiation of ferruginous quartzite was developed [6]. 


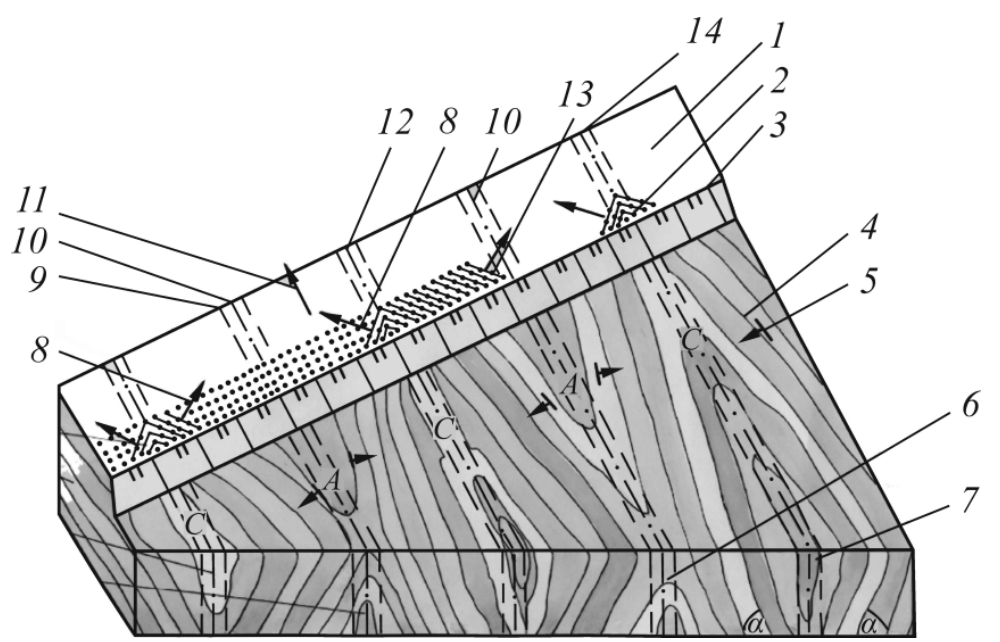

Fig. 2. Geological scheme of complex-structure body of ferruginous quartzite with location of blast holes and entry blasts: 1-block under blasting; 2, 13-communication line of simultaneously blasted charges; 3-line of formation of bench; 4-strike of folding; 5-dip of fold wings; 6, 7-cores of syncline and anticline folds; 8propagation of breakage wave; 9, 14-axial zones of folds; 10, 12-axes of pivots of syncline and anticline folds; 11 - mining front advance; $A$ and $C$ - axes of pivots of anticline and syncline folds, respectively.

It is very important to size the controlled fragmentation zone (radius) with regard to anisotropy in different directions: along and across bedding, and at different angles. Within the controlled fragmentation zone, the size of particles after blasts is no more than standard.

The theoretical formula for the controlled fragmentation zone along and across bedding is obtained in [12] and, considering the research findings in [12, 14], is given by:

$$
R=\frac{\sqrt{\pi}}{8} \frac{D \rho d_{0} c v}{\sigma_{1} \Phi^{0.5}(1-v)}\left(1-\frac{\mu v}{1-v}\right) \sqrt{\frac{d_{1}}{d_{2}}},
$$

where $D, \rho, d_{0}$ are the velocity of detonation, charge density and charge diameter, respectively; $c, v, \mu$ are the P-wave velocity, Poisson's ratio of joints and friction coefficient between them; $d_{1}, d_{2}, \Phi$ are the size of standard particle, size of joint and jointing index; $\sigma_{1}$ is the tensile strength limit.

For calculating $R$ in different directions, the numerical values of the parameters $c, v, \sigma_{1}, d_{2}$ are found experimentally in parallel and in perpendicular to bedding. Later research allowed a formula of $R$ with regard to different angles relative to bedding, $\beta$, in anisotropic rock mass:

$$
R=\frac{\sqrt{\pi}}{8} \frac{D \rho d_{0} c v}{\sigma_{1} \Phi^{0.5}(1-v)}\left(1-\frac{\mu \nu}{1-v}\right)(1+\cos \beta)^{0.5} \sqrt{\frac{d_{1}}{d_{2}}} .
$$

Here, the values of $c, v, \sigma_{1}, d_{2}$ are calculated as average irrespective of bedding orientation. The general radii are obtained at $\beta=0,90,180,270^{\circ}$.

However, the physico-technical analysis shows that under blasting in anisotropic rock mass in areas sloped at 30-60, 120-150, 210-240, 300-330 to bedding, joints will experience both compression and shearing. The theoretical studies yielded a formula of the radius of the controlled fragmentation zone under shearing $[13,14]$ :

$$
R=\frac{\sqrt{\pi}}{8} \frac{D \rho d_{0} c}{\sigma_{2} \Phi^{0.5}}\left(1-\frac{\mu \nu}{1-v}\right) \sqrt{\frac{d_{1}}{d_{2}}},
$$

where $\sigma_{2}$ is the shearing strength limit of a rock specimen. 
Size distribution in rock samples from areas $1-5$ in blasted block, \%

\begin{tabular}{c|c|c|c|c|c|c}
\hline \multirow{2}{*}{$\begin{array}{c}\text { Size of fractions, } \\
\mathrm{mm}\end{array}$} & \multicolumn{5}{|c|}{ Yield of fractions per areas $1-5$, Level $-10 \mathrm{~m}$} & \multirow{2}{*}{$\begin{array}{c}\text { Average yield } \\
\text { of fractions }\end{array}$} \\
\cline { 2 - 6 } & 1 & 2 & 3 & 4 & 5 & 69 \\
$250-400$ & 67 & 70 & 73 & 64 & 60 & 22 \\
$400-500$ & 23 & 22 & 13 & 27 & 25 & 9 \\
$>500$ & 10 & 8 & 4 & 9 & 15 & - \\
\hline
\end{tabular}

Formulas (1)-(3) include characteristics of scale III anisotropy such as tensile strength limit shearing strength limit; P-wave velocity in joint and Poisson's ratio, as well as scale II anisotropy such as size of joint and jointing index of rock mass. Scale III anisotropy characteristics govern spacing of simultaneously blasted holes in a row and spacing of short-delay blast rows. According to the mathematical analysis, the zone of fragmentation by blasting in an anisotropic jointed rock mass is noncircular.

Let us evaluate the controlled fragmentation zone radius in anisotropic ferruginous quartzite body in different directions: from formula (2) at 0,180 and $90,270^{\circ}$, from formula (3) at 30-60 ${ }^{\circ}$. The calculation parameters are: $D=3.6 \cdot 10^{3} \mathrm{~m} / \mathrm{s}$, explosive is Grammonit M-21, $\rho=0.85 \cdot 10^{3} \mathrm{~kg} / \mathrm{m}^{3}, d_{0}=0.25 \mathrm{~m}$, $\mu=0.45$ and $d_{1}=0.4 \mathrm{~m}$. Using the experimental data from [11], we assume for ferruginous quartzite that: $\sigma_{1}=13 \cdot 10^{6} \mathrm{~Pa}, c=5 \cdot 10^{3} \mathrm{~m} / \mathrm{s}, v=0.24, d_{2}=0.375 \mathrm{~m}, \sigma_{2}=26 \cdot 10^{6} \mathrm{~Pa}$ and $\Phi=80$. In view of the data from $[9,10]$, the shearing strength is twice as high as the tension strength.

The numerical calculations from (3) at the angles of 0 and $180^{\circ}$ to bedding yield $R=3.21 \mathrm{~m}$, and at $90,270^{\circ}-R=2.27 \mathrm{~m}$. The evaluation from (3) for the angle ranges $30-60^{\circ}, 120-150^{\circ}$ etc., where the governing load is shearing, offers $R=3.13 \mathrm{~m}$.

The geometrical constructions show that the zone of controlled fragmentation by blasting in the anisotropic rock mass is a scalene hexagon. To diminish the uncontrolled fragmentation zone, it is required to arrange simultaneously blasted holes in a line at an angle of $30-60^{\circ}$ to the axis of pivot of syncline and anticline folds (Fig. 2).

The theoretical analysis and commercial-scale application of the results on breakage of anisotropic rocks in Lebedinsky and Stoilensky open pit mines have proved that the more efficient arrangement of simultaneously blasted charges is a line at an angle of $5-60^{\circ}$ to the axis of pivot of syncline and anticline folds $[1,6,7]$ (Fig. 2). The entry blasts in blocks to be broken should be arranged in the zone of syncline fold; in case of two and more folds in a block, the entry blasts are primed simultaneously and damage waves are accumulated near the core of the anticline fold (Fig. 2). Spacing of charges and rows of simultaneous blasting should be selected in conformity with the approximately hexagon geometry of the fragmentation zone and equal (3-4)R.

The table gives information on size distribution measured after blasting in block 28 in the Stoilensky open pit mine using samples from areas 1-5. After blasting, it was pointed at good fragmentation of block toe and optimal size distribution $[1,6]$.

All these approaches and operations improve efficiency and reduce energy consumption in further processing of blasted rocks by $15-20 \%$, as well as decrease loss of useful components.

The discussed methods and designs of blasting with regards to geological and geophysical characteristics of rocks are applied at Lebedinsky and Stoilensky Mining and Processing Plants, KMA. Total volume of blasted rock blocks exceeds 600 ths $\mathrm{m}^{3}$.

\section{CONCLUSIONS}

Efficient blast impact on complex-structure bodies of ferruginous quartzite is based on generation of damage wave by a set of simultaneously blasted holes arranged in a line at an angle of $45-60^{\circ}$ to the axis of pivot of a syncline or anticline fold. In case of two and more folds in a block, entry blasts in synclines are primed simultaneously. 
The implemented research findings are applicable in operations in conformity with the standards and requirements of efficient subsoil management and geoecological safety during mine planning and blast pattern design at iron ore deposits. The results can be used in new open pit and underground mines to develop complex structure deposits of iron ore and other hard minerals.

\section{ACKNOWLEDGMENTS}

This study was supported by the Russian Science Foundation, project no. 16-17-00095.

\section{REFERENCES}

1. Anisimov, V.N., Substantiation of Iron Ore Mining and Blasting, Considering Geological and Geophysical Characteristics and the Rational Subsoil Use Standards, GIAB, 2015, no. 9, issue 33, pp. 1-23.

2. Oparin, V.N., Yushkin, V.F., Porokhosvkii, N.N., Grishin, A.N., et al., Effect of Large-Scale Blasting on Spectrum of Seismic Waves in a Stone Quarry, J. Min. Sci., 2014, vol. 50, no. 5, pp. 865-877.

3. Pershin, G.D. and Ulyakov, M.S., Enhanced Dimension Stone Production in Quarries with Complex Natural Jointing, J. Min. Sci., 2015, vol. 51, no. 2, pp. 330-334.

4. Gzogyan, T.N. and Gzogyan, S.R., Ferruginous Quartzites from Kimkan Deposit and Their Processing, J. Min. Sci., 2017, vol. 53, no. 1, pp. 147-154.

5. Yusupov, T.S., Urakaev, F.Kh., and Isupov, V.P., Prediction of Structural Chemical Change in Minerals under Mechanical Impact during Milling, J. Min. Sci., 2015, vol. 51, no. 5, pp. 1034-1040.

6. Anisimov, V.N., Procedure Blast Design and Blast Impact Evaluation in Milling and Processing of Ferruginous Quartzite, Considering Their Explosive and Magnetic Destruction, GIAB, 2012, no. 5, pp. 213-223.

7. Anisimov, V.N., Vzryvomagnitnaya destruktsiya kristallicheskikh materialov (gornykh porod) razlichnymi impul'snymi dinamicheskimi vozdeistviyami (Explosive-Magnetic Destruction of Crystalline Materials (Rocks) by Different Pulsed Dynamic Actions), Moscow: VU Aim. N.E. Zhukovskogo, 2008.

8. Rats, M.V., Neodnorodnost' gornykh porod i ikh fizicheskikh svoistv (Nonuniformity of Rocks and Their Physical Properties), Moscow: Nauka, 1968.

9. Mel'nikov, N.V., Rzhevsky, V.V., and Protod'yakonov, M.M. (Eds.), Spravochnik (kadastr) fizicheskikh svoistv gornykh porod (Reference Book-Cadastre of Physical Properties of Rocks), Moscow: Nedra, 1975.

10. Rzhevsky, V.V. and Novik, G.Ya., Osnovy fiziki gornykh porod (Basic Physics of Rocks), Moscow: Nedra, 1984.

11. Issledovanie napryazhenno-deformirovannogo sostoyania porod v tselikakh pri otrabotke Korobkovskogo mestorozhdeniya KMA etazhno-kamernoi sistemoi s uvelichennymi parametrami: otchet VIOGEM (Study of Stress-Strain State of Rock Pillars at the Korobkov Deposit under Stoping with Enlarged Parameters: VIOGEM Report), Belgorod, 1984.

12. Kutuzov, B.N. and Tyupin, V.N., Determination of Size of Controlled Fragmentation Zone under Blasting in Jointed Rock Mass, Gornyi Zhurnal, 1974, no. 8, pp. 30-35.

13. Tyupin, V.N., Raising the Efficiency of Blasting in Quarries, Proc. 1st Int. Sci. Conf. on Economic Management in Mineral Activities-EMMA, Hanoi, Vietnam, 2013, pp 303-307, 586-590.

14. Tyupin, V.N., Opasnye fizicheskie protsessy pri ekspluatatsii zheleznykh dorog (Hazardous Physical Processes in Operation of Railways), Chita: ZabIZHT, 2013. 